\title{
Thermodynamic Consideration of the Charge Transfer Interaction of the Donor: Acceptor Type between Chloranilic Acid and Haloperidol
}

\author{
Anthony Amaechi Attama, ${ }^{*}$ Petra Obioma Nnamani, Michael Umale Adikwu, and \\ Florence Obianuju AKIDI \\ Drug Delivery Research Unit, Department of Pharmaceutics, University of Nigeria; Nsukka 410001, Enugu State, Nigeria. \\ Received July 14, 2003; accepted November 4, 2003
}

The thermodynamic parameters of the charge transfer complex between chloranilic acid and haloperidol were studied. Haloperidol in pure form and in dosage form was assayed in this study. The method was based on charge transfer complex formation between the drug, which acted as an $n$-donor, and chloranilic acid, which acted as a $\pi$ acceptor in a non aqueous solvent. The complex stoichiometry was found to be $1: 2$ (haloperidol : chloranilic acid) with the maximum absorption band at a wavelength of $576 \mathrm{~nm}$. The complex obeyed Beer's law. The thermodynamic parameters investigated included stability constant, molar absorptivity, free energy change, enthalpy, and entropy. The method was successfully applied in the analysis of commercially available haloperidol tablets without interference from its excipients, with good precision and reproducibility, compared with the official assay method (non aqueous titration) described for haloperidol in the compendium.

Key words thermodynamic parameter; charge transfer complex; chloranilic acid; haloperidol assay

The term charge transfer denotes a certain type of complex, which results from interaction of an electron acceptor and an electron donor with the formation of weak bonds. ${ }^{1)}$ Charge transfer complexes result from a donor-acceptor mechanism of the Lewis acid-base reaction between two or more different chemical constituents. The formation of electron donor-acceptor complexes can be rapidly assessed for its validity as a simple qualitative and quantitative analytical method for many drug substances that can act as electron donors. Chloranilic acid and other $\pi$-acceptors as well as sigma $(\sigma)$ acceptors have been successfully utilized in the determination of a variety of electron-donating basic compounds. $^{2-5)}$ Haloperidol is an antipsychotic agent that alters the mental state and behavior in a predictable manner. ${ }^{6)}$ It is one of the most potent antipsychotic agents available and is less sedative than the phenothiazines. ${ }^{7)}$ A non aqueous assay procedure was described for haloperidol in the compendia. ${ }^{8,9}$ ) Based on that, an attempt was made to devise an alternative assay procedure for haloperidol both in dosage form and in pure form. The aim of this study therefore was to develop an assay procedure for the analysis of haloperidol both in pure form and in dosage form.

\section{Experimental}

Materials The following materials were procured from their local suppliers: haloperidol pure powder and Haldol tablets (Janssen Pharmaceutica), Serenace tablets (Morison), unbranded haloperidol tablets (Waterland, The Netherlands), chloranilic acid (Merck, Germany) and 1,4-dioxane (analytical grade, BDH, U.K.), and chloroform (May \& Baker, U.K.) was redistilled from a batch procured from the supplier. Other reagents and solvents were of analytical grade and were used as such. All laboratory reagents were freshly prepared.

Preparation of Standard Solutions Chloranilic Acid: A stock solution of chloranilic acid with a concentration of $2.39 \times 10^{-2} \mathrm{M}$ was prepared by dissolving $0.5 \mathrm{~g}$ of chloranilic acid powder accurately weighed in 1,4-dioxane and making up to $100 \mathrm{ml}$ with the same solvent. Further dilutions to produce lower concentrations were carried out using 1,4-dioxane.

Haloperidol: A standard solution of haloperidol was prepared by accurately weighing $0.4525 \mathrm{~g}$ of pure haloperidol into a $100-\mathrm{ml}$ volumetric flask using an analytical balance (Sauter KGD 7470, Germany). The flask was made up to volume with chloroform to provide a $1.20 \times 10^{-3} \mathrm{M}$ solution.

Absorption Spectra A 2-ml volume of the chloranilic acid stock solution was scanned through a double-beam UV-vis spectrophotometer (SP8-

* To whom correspondence should be addressed. e-mail: aaattama@yahoo.com
100 , Pye Unicam) to determine its wavelength of maximum absorption. Mixing $2 \mathrm{ml}$ of the chloranilic acid solution with $2 \mathrm{ml}$ of the haloperidol standard solution, and making it up to $5 \mathrm{ml}$ with 1,4-dioxane developed a color. The wavelength of maximum absorption of the resulting solution was thereafter determined in the spectrophotometer above.

Stoichiometric Determination of Composition of Complexes Job's method of continuous variation was employed. ${ }^{10)}$ A $1.20 \times 10^{-3}$ M solution of haloperidol in chloroform and $1.20 \times 10^{-3} \mathrm{M}$ solution of chloranilic acid in 1,4-dioxane were used in the experiment. A series of 5-ml volumes of mixtures of master solutions comprising complementary proportions of the two solutions $(0.5: 4.5 ; 1.0: 4.0 ; \ldots 4.5: 0.5)$ were transferred into different test tubes and the complex formed for each reaction mixture was allowed to stand for $60 \mathrm{~min}$ at room temperature before analysis at $576 \mathrm{~nm}$. A blank solution of chloranilic acid $(2 \mathrm{ml})$ and chloroform $(3 \mathrm{ml})$ was used.

Determination of Stability Constant, Molar Absorptivity, and Thermodynamic Parameters Serial volumes of 0.8 to $1.8 \mathrm{ml}$ of $1.59 \times 10^{-3} \mathrm{M}$ haloperidol solution in $0.2-\mathrm{ml}$ steps were transferred to different test tubes. The solutions were diluted to $3 \mathrm{ml}$ with chloroform, $2 \mathrm{ml}$ of a $1.26 \times 10^{-3} \mathrm{M}$ solution of chloranilic acid in 1,4-dioxane was added, and the contents were mixed by gentle shaking. Each test tube was allowed to stabilize for $60 \mathrm{~min}$ at room temperature, and absorbance measurements were taken in a spectrophotometer at $576 \mathrm{~nm}$. Further analyses of the reaction mixture were done at temperatures of 40,50 , and $60^{\circ} \mathrm{C}$. The temperatures were maintained by keeping the reaction mixtures in a thermostated water bath (Memmert).

Assay Procedure for Haloperidol Tablets Twenty Haldol tablets were finely powdered and an amount equivalent to $5 \mathrm{mg}$ of haloperidol base was accurately weighed. This was carefully transferred into a clean beaker containing $5 \mathrm{ml}$ of chloroform and shaken for $5 \mathrm{~min}$ to allow the drug to dissolve. The solution was then filtered to remove the excipients. The solution was thereafter made up to $10 \mathrm{ml}$ with chloroform to provide a theoretical $1.33 \times 10^{-3} \mathrm{M}$ solution of haloperidol. To $1 \mathrm{ml}$ of the resulting solution was then added $2 \mathrm{ml}$ of equimolar chloranilic acid solution, and the absorbance was determined at $576 \mathrm{~nm}$. Percentage recoveries of haloperidol from the dosage form were calculated by reference to the Beer's plot. This procedure was repeated for Serenace tablets and unbranded haloperidol tablets.

\section{Results and Discussion}

Absorption Spectra A solution of chloranilic acid in 1,4-dioxane had a golden yellow color with maximum wavelength at $436 \mathrm{~nm}$ (Fig. 1). This is in agreement with the results of an earlier preliminary study involving haloperidol and chloranilic acid complexation. ${ }^{11)}$ The purple color obtained on reaction of the yellow chloranilic acid solution and the colorless solution of the drug in chloroform was suggestive of a charge transfer complex formation, resulting in the 


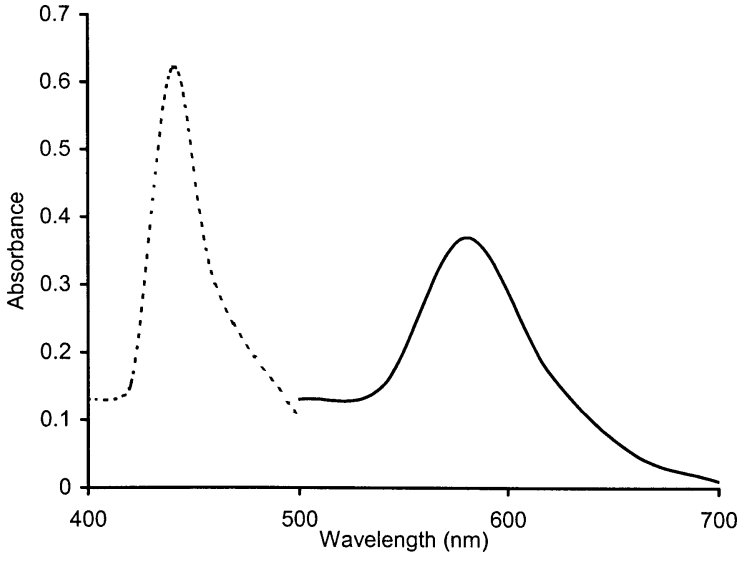

Fig. 1. Absorption Spectra

Initial concentration of chloranilic acid was $2.39 \times 10^{-2} \mathrm{M}$ and haloperidol was $1.2 \times 10^{-3} \mathrm{M}$, the final concentration of chloranilic acid and haloperidol in the complex $(5 \mathrm{ml})$ was $9.56 \times 10^{-3} \mathrm{M} / 4.80 \times 10^{-4} \mathrm{M}$. - - - Chloranilic acid, - chloranilic acid-haloperidol complex.

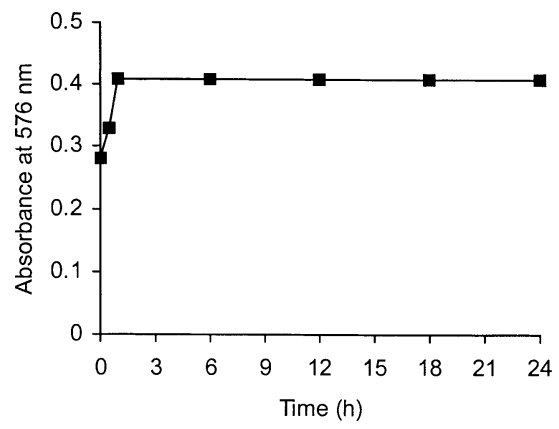

Fig. 2. Time-Absorbance Relationship for the Complex

scanning of the complex in the visible range of 400 $700 \mathrm{~nm}$, which showed a maximum peak at $576 \mathrm{~nm}$ (Fig. 1). ${ }^{11)}$ Although the complex was formed instantaneously, constant absorbance readings were obtained after no less than 60 min of standing at room temperature and remained constant for at least $24 \mathrm{~h}$ (Fig. 2). The absorption band of chloranilic acid showed a bathochromic shift (shift to a longer wavelength).

Beer's Plot for Haloperidol-Chloranilic Acid Complex Beer's law was thus obeyed. At $576 \mathrm{~nm}$, a linear relationship was obtained $(r=0.993)$ between the absorbance and the concentration over the entire range studied. The regression equation of the line as derived by the method of least squares is:

$$
A_{576 \mathrm{~nm}}=0.0251[D]-0.0011
$$

where $[D]$ is the concentration of haloperidol in milligrams per $100 \mathrm{ml}$.

Job's Plot for Haloperidol-Chloranilic Acid Complex The stoichiometric ratio of the reactants was determined using Job's method of continuous variation. ${ }^{10)}$ A $1: 2$ ratio of charge transfer complex was indicated for the chloranilic acid-haloperidol interaction (Fig. 3), which may be represented as:

$$
2 A+D=\left[D: A_{2}\right]
$$

where $A$ is the acceptor (chloranilic acid), $D$ is the donor (haloperidol), and $\left[D: A_{2}\right]$ represents the complex formed.

This indicates the presence of more than one binding site

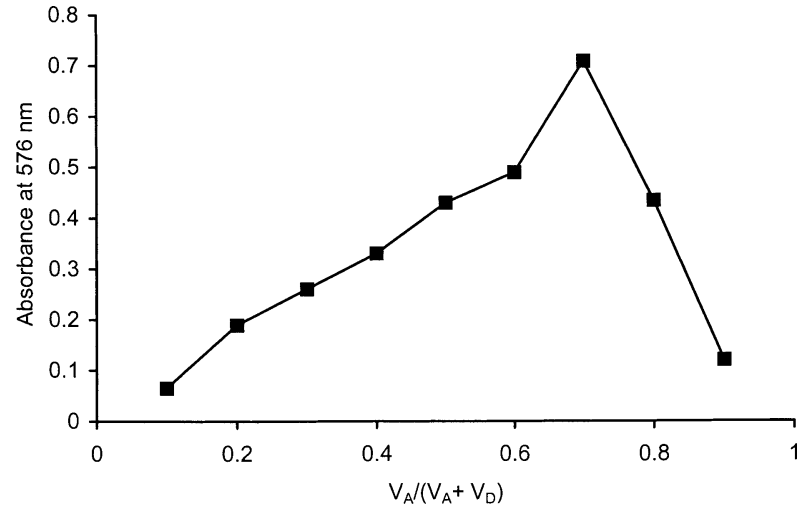

Fig. 3. Job's Plot for Haloperidol-Chloranilic Acid Complex

Initial concentrations used were: $1.2 \times 10^{-3} \mathrm{M}$ haloperidol and $1.2 \times 10^{-3} \mathrm{M}$ chloranilic acid.

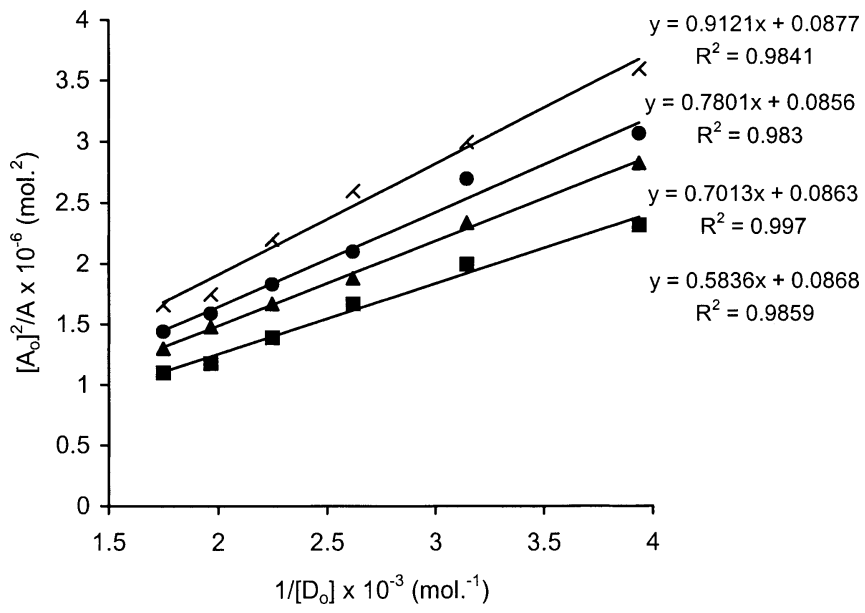

Fig. 4. Modified Benesi-Hildebrand Plot for the Haloperidol-Chloranilic Acid Complex

$30{ }^{\circ} \mathrm{C}, \Delta 40^{\circ} \mathrm{C}, 50{ }^{\circ} \mathrm{C}, \wedge 60^{\circ} \mathrm{C}$.

for chloranilic acid in haloperidol. This finding was anticipated because of the probable presence of a double strongly electron-donating center in the molecular structure of haloperidol.

Stability Constant, Molar Absorptivity, and Thermodynamic Parameters The molar absorptivity and association constant for the haloperidol-chloranilic acid complex were evaluated using a modification of the Benesi-Hildebrand equation. ${ }^{12)}$

$$
\frac{\left[A_{\mathrm{o}}\right]^{2}}{A_{\lambda}^{\left[D: A_{2}\right]}}=\frac{1}{E_{\lambda}^{\left[D: A_{2}\right]}}+\left(\frac{1}{K_{\mathrm{c}}^{\left[D: A_{2}\right]} E_{\lambda}^{\left[D: A_{2}\right]}}\right)\left(\frac{1}{\left[D_{\mathrm{o}}\right]}\right)
$$

where $\left[D_{0}\right]$ and $\left[A_{0}\right]$ are initial concentrations of the reactants, $A_{\lambda}^{\left[D: A_{2}\right]}$ is the absorbance of the complex at $576 \mathrm{~nm}$, $E_{\lambda}^{\left[D: A_{2}\right]}$ is the molar absorptivity of the complex at $576 \mathrm{~nm}$, and $K_{\mathrm{c}}^{\left[D: A_{2}\right]}$ is the stability constant.

A plot of $\left[A_{0}\right]^{2} / A_{\lambda}^{\left[D: A_{2}\right]}$ against $1 /\left[D_{0}\right]$ is shown in Fig. 4. The intercepts and the slopes of the regression lines were used to obtain the values of $E_{\lambda}^{\left[D: A_{2}\right]}$ and $K_{\mathrm{c}}^{\left[D: A_{2}\right]}$, respectively, at constant $\left[A_{\mathrm{o}}\right]$. The molar absorptivities calculated were almost constant at the different temperatures. This was expected since ideally it should not vary. However, the variation was not highly significant $(p<0.05)$. The stability constants 


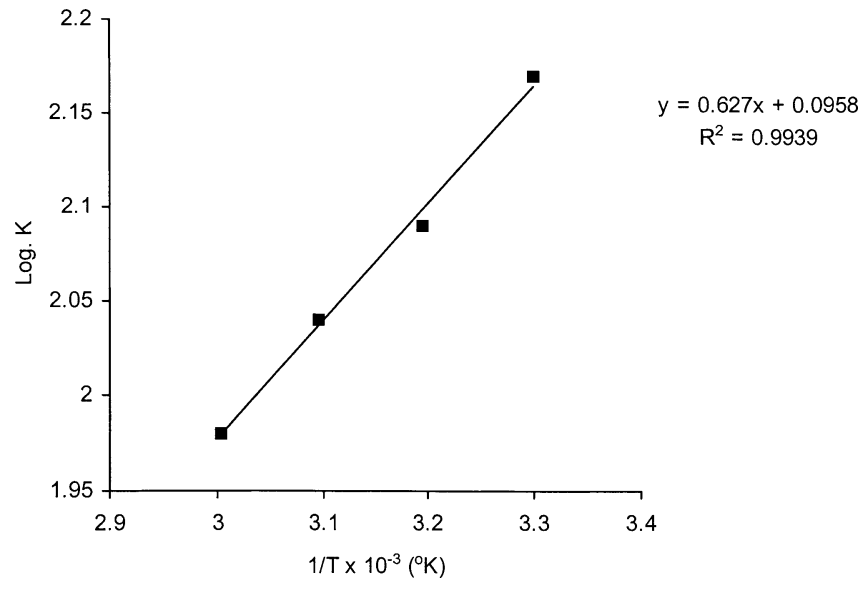

Fig. 5. $\log K$ of the Haloperidol-Chloranilic Acid Interaction versus $1 / T$

Table 1. Molar Absorptivity, Stability Constants, and Thermodynamic Parameters of the Charge Transfer Complexes

\begin{tabular}{cccccc}
\hline \hline $\begin{array}{c}\text { Temp. } \\
(\mathrm{K})\end{array}$ & $\begin{array}{c}K_{\mathrm{c}} \\
\left(\mathrm{mol}^{-1}\right)\end{array}$ & $\begin{array}{c}\Delta G^{\circ} \\
\left(\mathrm{J} \cdot \mathrm{mol}^{-1}\right)\end{array}$ & $\begin{array}{c}\Delta H^{\circ} \\
\left(\mathrm{J} \cdot \mathrm{K}^{-1} \mathrm{~mol}^{-1}\right)\end{array}$ & $\begin{array}{c}\Delta S^{\circ} \\
\left(\mathrm{J} \cdot \mathrm{K}^{-1} \mathrm{~mol}^{-1}\right)\end{array}$ & $\begin{array}{c}\text { Molar } \\
\text { abs. }\end{array}$ \\
\hline 303 & 148.7 & -1951.72 & & 6.40 & 11.52 \\
313 & 123.1 & -1918.31 & -12.01 & 6.09 & 11.59 \\
323 & 109.7 & -1914.64 & & 5.89 & 11.68 \\
333 & 96.0 & -1891.26 & & 5.64 & 11.40 \\
\hline
\end{tabular}

showed a reduction with increase in temperature. Increase in temperature may have led to the dissociation of the formed complexes. These are presented in Table 1.

The standard enthalpy change, $\Delta H^{\circ}$, of the haloperidolchloranilic acid interaction was obtained from Eq. 4 below by plotting $\log K_{\mathrm{c}}^{\left[D: A_{2}\right]}$ against the reciprocal of absolute temperature, $T$, where it was calculated from the slope of the regression line. The plot is shown in Fig. 5 and the result is presented in Table 1.

$$
\log K_{\mathrm{c}}^{\left[D: A_{2}\right]}=\frac{-\Delta H^{\circ}}{2.303 R T}+\text { const. }
$$

where $R$ is the gas constant.

Similarly, Gibb's free energy $\left(\Delta G^{\circ}\right)$ and the entropy $\left(\Delta S^{\circ}\right)$ were calculated respectively from Eqs. 5 and 6 , and the results are presented in Table 1.

$$
\begin{aligned}
& \Delta G^{\circ}=-R T \ln K_{\mathrm{c}}^{\left[D: A_{2}\right]} \\
& \Delta G^{\circ}=\Delta H^{\circ}-T \Delta S^{\circ}
\end{aligned}
$$

The interaction between haloperidol and chloranilic acid occurs spontaneously and the negative $\Delta H^{\circ}$ in Table 1 is itself confirmation of a spontaneous reaction. $\Delta H^{\circ}$ becomes more negative as the stability constant for molecular complexes increases. The high negative value of $\Delta H^{\circ}$ and the high values of the stability constants as is evident in Table 1 are pointers to the strength of the bonding between haloperidol and chloranilic acid, and the high stability of the resultant charge transfer complex. $\Delta G^{\circ}$ and $\Delta S^{\circ}$ also decreased slightly as the temperature increased. Positive values of $\Delta S^{\circ}$ are also indicative of a spontaneous reaction.

The validity of the regression equation earlier stated for the calibration of the haloperidol-chloranilic acid complex was assessed in its determination in pure sample and in tablet
Table 2. Result of Haloperidol Assay by Charge Transfer Complexation

\begin{tabular}{lrrrr}
\hline \hline \multirow{2}{*}{ Parameter } & & \multicolumn{3}{c}{ Tablets $^{a)}$} \\
\cline { 3 - 5 } & Pure sample & \multicolumn{1}{c}{$\mathrm{A}$} & \multicolumn{1}{c}{$\mathrm{B}$} & \multicolumn{1}{c}{$\mathrm{C}$} \\
\hline Mean recovery (\%) $^{b)}$ & 100.13 & 100.11 & 100.41 & 99.98 \\
Standard deviation $^{c}$ & 1.21 & 1.14 & 1.17 & 1.07 \\
$t$ calculated $^{c}$ & 1.71 & 1.05 & 0.97 & 0.94
\end{tabular}

a) Haldol tablets manufactured by Janssen (A), Serenace tablets manufactured by Morison (B), unbranded haloperidol tablets manufactured by Waterland (C). b) Mean for 10 determinations; percentage recovery from the label claim amount $(5 \mathrm{mg}) . \quad c)$ The value for $t$ theoretical at $\alpha=0.025$ is 1.96 .

Table 3. Assay Results for Haloperidol in Pure Sample and in Tablets Using the Official Method

\begin{tabular}{lrrrr}
\hline \hline \multirow{2}{*}{\multicolumn{1}{c}{ Parameter }} & Pure sample & \multicolumn{3}{c}{ Tablets $^{a)}$} \\
\cline { 3 - 5 } & & A & B & C \\
\hline Mean recovery (\%) & & & & \\
Standard deviation $^{b}$ & 99.98 & 99.93 & 99.99 & 99.95 \\
$t$ calculated $^{c}$ & 1.25 & 1.22 & 1.37 & 1.87 \\
& 1.79 & 1.14 & 1.45 & 1.21 \\
\hline
\end{tabular}

$a), b), c$ ) are the same as in Table 2. Results confirmed the data obtained from the preliminary study. ${ }^{11)}$

dosage form. This completely agrees with the earlier preliminary work done on this compound. ${ }^{11)}$ Table 2 shows the accuracy of the proposed method and Table 3 the result for the official method. Recovery experiments carried out on haloperidol in pure sample and in tablet dosage forms showed high quantitative recoveries with low standard deviations. ${ }^{11)}$ The performance of the proposed method was judged through calculation of Student's $t$-value. At the $95 \%$ level of probability, the calculated values of $t$ do not exceed the theoretical values. This is an indication that the proposed method gives results not significantly different from the true values according to label claims and lends further confirmation to the high accuracy of the method. The accuracy of the method was not interfered with by the presence of auxiliary substances used in the tablet manufacture, since the haloperidol base was extracted before analysis. Compared with the official method, ${ }^{8,9)}$ the proposed method is simpler, faster, and more sensitive, making its use in drug analysis acceptable.

\section{Conclusions}

A charge transfer complexation between haloperidol and chloranilic acid occurred at a $1: 2$ stoichiometry, with maximum absorption at $576 \mathrm{~nm}$. Thermodynamically, the complex was found to be very stable at room temperature. This method was used to assay haloperidol in pure form and in some dosage forms with good precision and accuracy compared with the official non aqueous titration.

\section{References}

1) Mulliken R. S., J. Am. Chem. Soc., 72, 600-608 (1950).

2) Agarwal S. P., El-sayed M. A., Analyst (London), 106, 1157-1162 (1981).

3) Adikwu M. U., Ofokansi K. C., J. Pharm. Biomed. Anal., 16, 529532 (1997).

4) Adikwu M. U., Ofokansi K. C., Attama A. A., Chem. Pharm. Bull., 47, 463-466 (1999).

5) Adikwu M. U., Ofokansi K. C., Attama A. A., Biol. Pharm. Bull., 21, 1243-1246 (1998).

6) Wallace L. T., "The Science and Practice of Pharmacy," 19th ed., Vol. 
II, ed. by Genarro A. R., Mack Pub. Co., Easton, 1995, pp. 11801185.

7) Hollister L. E., "Basic and Clinical Pharmacology," 6th ed., PrenticeHall, London, 1995, pp. 432-435.

8) "British Pharmacopoeia," Her Majesty's Stationery Office, London, 1998.

9) “European Pharmacopoeia," Council of Europe, Strasbourg, 2002, pp.
$1288-1289$.

10) Job R., "Advanced Physicochemical Experiments," Pitman, London, 1964, p. 54.

11) Attama A. A., Nnamani P. O., Adikwu M. U., Akidi F. O., STP Pharma. Sci., 13, 419-421 (2003).

12) Benesi H. A., Hildebrand J. H., J. Am. Chem. Soc., 70, 2032-2033 (1949). 